\title{
Metalinguagem como repetição e diferença em Um sopro de vida, de Clarice Lispector
}

\author{
José Niraldo de Farias
}

Embora nào se possa afirmar ter havido no Brasil um movimento que justifique a existência de uma vertente metaficcional durante os anos 70 , tal como houve, por exemplo, na Espanha, o uso da metalinguagem pela narrativa teve sua importância e lugar, ganhando força e atingindo seu ápice com a obra literária de Clarice Lispector. A consciência da literatura como processo permeia seus romances desde o início. Do primeiro ao último livro, a preocupaçào com o ato da escritura está sempre presente. Em nenhuma de suas obras, contudo, esta obsessão apresentase tão preeminente quanto em Um sopro de vida (SV) (Lispector,1978). Neste romance, a angústia de escrever torna-se quase que seu tema único.

Nossa intenção no presente trabalho é tentar entender certos mecanismos da metaficçào no referido romance de Lispector, aproximando este procedimento literário de duas categorias filosóficas: a repetição e a diferença. Neste sentido, a obra Diferença e Repetição, de Gilles Deleuze, será decisiva para nossa análise. O estudo do filósofo francês será basilar no sentido de discernir a natureza dialética da metaficçào.

Deleuze (1976) parte de Hume: "A repetição não muda nada no objeto que se repete, mas muda alguma coisa no espírito que a contempla."” A questão colocada por Deleuze é de como a repetição pode mudar alguma coisa em cada caso ou em cada elemento repetido, se a repetição implica inevitavelmente uma independência total a cada momento que ocorre. Em outras palavras, como pode alguma coisa que é inerentemente repetitiva mudar uma outra coisa? A única resposta possível seria um paradoxo: só podemos falar de repetiçào através da diferença.

Nossa teoria é de que o ato de refletir sobre si mesmo, que caracteriza o romance moderno, se constitui num processo de repetiçào. Há uma certa redundância no procedimento metaficcional. Expor os artificios, revelar os mecanismos da ilusão; apontar para o texto em si é, de algum modo, interromper o fluxo natural da

I"La répétition ne change rien dans l'objet qui se repète, mais elle change quelque chose dans l'esprit qui la contemple." Cf. Deleuze, Gilles. Différence et répétition. Paris, Presses Universitaires de France, 1976. p. 12. 
linguagem, introduzindo uma espécie de duplicação. Especular sobre o processo é, até certo ponto, repetir este mesmo processo. Por outro lado, esta repetição nunca é a mesma. Implica sempre um movimento, um deslocamento em direçào à diferença. Neste sentido, a metaficção é ao mesmo tempo reprodução do Mesmo e avanço em direçào ao Outro.

Um sopro de vida é um exemplo perfeito deste movimento dialético do modo metaficcional de discurso. Lispector divide a narrativa em dois níveis: o primeiro está representado pela personagem denominada "autor"; o segundo, pela personagem Angela Pralini, objeto da metalinguagem deste "autor." Poderíamos dizer que o discurso de Angela Pralini está em relação de redundância no que diz respeito ao discurso de "autor." Em alguns momentos da narrativa, fica difícil distinguir um discurso do outro, exceto pelo fato de que a escritora usa o procedimento dramático de separar e identificar os nomes como em uma peça de teatro. Nào é apenas a estrutura deste romance que o faz exemplo perfeito do movimento que vai da repetiçào à diferença. No nível do conteúdo, este problema é explicitamente debatido pelo narrador:

O que sustenta e equilibra o homem são suas pequenas manias $e$ hábitos. E dão realie a seu desenvolvimento porque tudo o que se repete muito termina por aprofundar uma atitude e dar-lhe espaço. Mas para se experimentar uma surpresa é necessário que a rotina dos hábitos e manias seja por qualquer motivo suspensa. Com que fico? Com o aprofundamento critico ou com uma surpresa estimulante? Acho que fico com os dois, anarquicamente intercalados ou simultâneos (SV, p. 85).

Esta profunda reflexào sobre o hábito é uma tentativa de desvendar e compreender o seu mistério. A acumulação de atos repetidos que caracteriza a existência humana é magnanimamente aceita. Mas esta aceitaçào só se dá sob uma condiçào: a de que esta seja um meio para a transcendência. Para experimentar a surpresa faz-se necessário quebrar os hábitos, suspender os eventos monótonos da vida diária. Nesse sentido, o hábito constitui-se numa teia aprisionadora do ser humano. Dessa forma, torna-se essencial remover o véu que recobre este nebuloso mundo que nos priva de ricas experiências.

Samuel Butler, em Life and Habit, afirma que nào podemos realizar nada com perfeiçào a não ser inconscientemente e não podemos realizar nada inconscientemente até podermos realizá-lo com perfeição (1984:294). Em sua trajetória ao Desconhecido, Lispector entende perfeitamente a necessidade deste movimento ambíguo que vai da banalidade dos repetidos eventos até à grandiosidade da paixào. 
De acordo com Ravaisson, o hábito é sempre o estado de permanência, no qual a mudança é sempre transitória, evanescente. O hábito sempre subsiste à mudança, da qual resulta. Ele nào apenas sobrevive à alteração que nào está mais lá, mas também àquela que ainda nào está lá, àquela que é apenas uma possibilidade (1984:52). É exatamente esta possibilidade de mudança que a rotina tenta mascarar e controlar que Lispector persegue por intermédio de um velho hábito: escrever. A metaficção é, nesse sentido, um eficiente procedimento para despertar este velho hábito. É indispensável estar atento a cada momento da vida, tornando-o singular e único. O processo de escrever nào pode se tornar um hábito a mais, posto que é a única forma que o autor encontra para iluminar a vida:

E não agüento o cotidiano. Deve ser por isto que escrevo. Minha vida é um tunico dia. E é assim que o passado me épresente e futuro. Tudo numa só vertigem (SV, p.17).

Ao discutir o processo de criaçào, o autor altera o objeto literário, apresentando ao leitor, através da repetiçào, um elemento de diferença. Como um discurso sobre outro discurso, a metaficçào poder ser interpretada como repetiçào, mas esta duplicaçào é também uma estratégia para introduzir a diferença. Como afirma Deleuze, "a diferença habita a repetição" (1976:103). A repetição ganha assim um novo sentido, passando a ser mais do que pura imitaçào ou duplicaçào, uma vez que é engendrada pela própria diferença.

O narrador exerce influência na personagem: sua vocação pela transcendência - incluindo as crenças misteriosas - é imitada por Angela. Mas ele também é impulsionado por suas próprias experiências. Em Além do principio metaficional, Spires afirma que a metaficçào ocorre quando o texto rompe intencionalmente com as convençòes arbitrárias da ficçào (1984:18). No caso de Um sopro de vida, a idéia pode ser perfeitamente aplicada. O narrador, também um personagem do livro, refere-se a Angela Pralini como um produto de sua criaçào. Ele comenta suas atitudes, especula sobre sua existência e determina seu destino. Na primeira parte do romance, o narrador (autor) conjectura sobre a necessidade ou nào de dar vida a Angela Pralini:

O resultado disso tudo é que vou ter que criar um personagem mais ou menos como fazem os novelistas, e através da criação dele para conhecer: Porque eu sozinho não consigo: a solidão, a mesma que existe em cada um, me faq inventar (SV, p.18). 
A violaçào das regras narrativas - criando novas regras - reside não apenas no relacionamento entre os personagens, mas também no fato de que não há história alguma, no sentido tradicional do termo. O diálogo entre Angela Pralini e o "autor" nào é um diálogo no sentido comum da expressào. A suposta conversação entre os dois personagens reduz-se a fragmentos, confissões e impressões sobre a vida e a experiência humana. Nào há enredo neste romance; o único enredo é o romance em si, o problema da criaçào e as questões existenciais levantadas pelo narrador. Nào há mais sentido em descrever fatos. Os únicos fatos importantes são a expressão e o silêncio:

EU PASSO PELOS FATOS o mais rapidamente possivel porque tenho pressa. A meditação secretissima me espera. Para escrever eu antes me despojo das palavras, prefiro palavras pobres que restam. Rapidamente dou os traços biográficos de Angela Pralini: rapidamente porque dados e fatos me chateiam (SV, p. 39).

A fragmentação da narrativa é, no entanto, resultado do caráter lírico do discurso do autor. O tom confessional deste romance provoca um fosso na linguagem, interceptando o fluxo da narraçào e criando descontinuidades e incongruências. A falibilidade da existência é comprovada pelo processo que questiona a autoridade da linguagem:

Eu escrevo por intermédio de palauras que ocultam outras. É que as verdadeiras não podem ser denominadas. Mesmo que eu não saiba quais são as "verdadeiras palavras," eu estou sempre aludindo a elas. Meu espetacular e continuo fracasso prova que existe seu contrário: o sucesso (SV, p. 72).

Este conjunto de disjunçòes e divergências demonstra que o autor, como simples ponto de subjetivação, é temporário e evanescente. O processo de fragmentação é, contudo, um movimento em direção à possível reunificação através da linguagem. Esta reunificaçào é, contudo, impossível. Certos traços residuais do autor em carne e osso permanecem na narrativa. No entanto, ainda que possamos provar a coincidência desses elementos lendo a biografia da autora, estas marcas no seu discurso têm uma conotaçào diferente. O fato de sabermos que Clarice Lispector, que estava morrendo de câncer e que tinha um cachorro de estimação chamado Ulisses, nào altera em nada a dimensào da personagem Angela Pralini:

\section{Ter contacto com a vida animal é indispensável à minha saúde}


psiquica. Meu cão me revigora toda. Sem falar que dorme às vezes aos meus pés enchendo o quarto da cálida vida úmida. O meu cão me ensina a viver. Ele só fica "sendo." "Ser" é a sua atividade (SV, p. 57).

A introduçào de certos elementos biográficos engendra a presença de um outro personagem na narrativa: o autor ele mesmo. Este procedimento torna-se evidente, quando a escritora coloca a penúltima frase do romance entre aspas: “Eu... eu... não. Não posso acabar", (SV, p.162).

Esta frase tem múltiplos e ambíguos significados. Tanto pode significar que ela se sente incapaz de terminar o livro, quanto pode referir-se à impossibilidade de terminar sua própria vida. Mas pode também significar que a linguagem nunca chega a um fim; o autor é apenas um dentre os inúmeros pontos de subjetivação desta contínua linha intersticial: o discurso literário. A busca de eternidade é encontrada na alteraçào qualitativa operacionalizada pelo texto:

Ah, como é ampla a eternidade. Pois foi isso o que eu vi: a amplidão serena da eternidade, o gosto do eterno. Então o corpo antes todo fraco $e$ trêmulo tomou um vigor de recém-nascido no seu primeiro grito esplático no mundo da lũ. De pé como um talo de trigo, jorrei-me em Ti e livrei-me de ter alma particular: Eu era a alma geral do mundo (SV, p.138).

Essa dissoluçào cósmica da alma tem sua contrapartida na maneira como o autor lida com a linguagem. Os romances de Clarice estào mais preocupados com a relaçào entre as palavras do que com a relação entre palavras e realidade. Como já nos ensinou Borges, nào há necessidade de o escritor preocupar-se com a realidade, pois esta é uma circunstância inescapável; e, mesmo quando lidamos com o jogo de oposiçòes irresolvíveis no reino da linguagem, estamos sempre lidando com a realidade, porquanto existem sempre certos elementos transbordando o aparentemente fechado sistema lingüístico. $O$ fato é que linguagem e realidade estão tào intimamente relacionados que se torna impossivel imaginar um sem o outro.

Para Robert Scholes, " a linguagem em si assume sempre um iontexto mais amplo. Ela não pode nunca ser auto-referencial porque, para interpretá-la, nós devemos colocá-la dentro de uma moldura de referênicia que será sempre temporal e cultural' (1979:15), ${ }^{2}$ É precisamente esta

2 "language itself always assumes a larger context. It can never be self-referential, because in order to interpret it we must locate it in a frame of reference which is ineluctably temporal and cultural. Scholes, Robert. Fabulation and metafiction. Urbana, University of Illinois Press, 1979. 
temporalidade que Lispector tenta deslocar. O caráter de auto-reflexividade da escritora brasileira desenraíza as palavras, retirando-as do seu contexto social e cultural, dando-lhes uma certa claridade e, ao mesmo tempo, carregando-as de novas conotações. Num nível mais superficial, parece não haver nenhum hermetismo no estilo de Clarice; ela escreve dentro das normas do português padrão culto. A maneira como ela organiza as palavras é, no entanto, inovadora. Essa inovação só é perceptivel, contudo, nas sutis frestas do discurso. Apesar da aparente simplicidade de sua escritura, é apenas através de grande esforço que o leitor pode construir o significado de seus romances. Essa característica de Um sopro de vida, por exemplo, é resultado da preocupação do escritor com o que a linguagem pode realizar. Liberando as palavras de sua aderência ao mundo externo, o autor engendra outros significados, criando o que ele mesmo chama de "visão do esplendor." Neste processo, a metaficçào é essencial: "meu ideal seria pintar um quadro de um quadro" (SV, p.149).

Roland Barthes define metalinguagem como um processo no qual "os significados do segundo sistema sào constituídos por signos do primeiro” (1980:98). A semiótica como um sistema de segunda ordem que toma outras linguagens como objeto é, dessa forma, considerada como metalinguagem. O semiólogo francês afirma que a noçào de metalinguagem nào deve ser confinada às linguagens científicas. Pode também ser aplicada à linguagem comum. Em alguns exemplos, no entanto, nós teríamos que lidar com um conjunto complexo no qual a metalinguagem seria eventualmente captada em um processo de conotação.

$\mathrm{Na}$ ficção, este processo metalingüístico está sempre inflacionado de conotaçòes. Não apenas porque o autor parte usualmente de um sistema inerentemente sobrecarregado de sentido, mas também porque o escritor intencionalmente tenta incrementar as múltiplas ambigüidades da linguagem, criando um vertiginoso mundo de significaçòes.

Para Deleuze (1976:288), a repetição nào é apenas uma questào de identidade com o Mesmo. Em vez de "intercambiar o similar e identificar o mesmo, esta autentica o diferente." A repetição não deve ser interpretada como mera reprodução do idêntico. Imersa na natureza, ela catapulta a realidade em infinitas e divergentes séries.

A repetiçào cristà de Kierkegaard nào é, neste sentido, compatível com a teoria deleuziana. O teocentrismo daquele vai de encontro ao descentramento proposto pelo teórico francês. É também diferente da noçào nietszcheana desta mesma categoria proposta na idéia do eterno retorno. Na repetiçào cristà, tudo retorna uma vez e para sempre; "a riqueza de Jó e o filho de Abraão, o corpo ressurgido e recuperado." No eterno retorno, a repetição não aspira ao recentramento 
do círculo. Ao contrário, no circulo de Dionísio, Cristo não retornará. A relaçào que o filósofo dinamarquês estabelece entre verdade e divindade é rejeitada pela ordem do Anticristo.

Um sopro de vida apresenta, de certa forma, uma certa conexào com esta idéia de divindade. Essa preocupaçào com transcendência e comunicaçào com Deus é endêmica à obra de Lispector:

Deus não foi feito para nós. Nós que fomos feitos para Ele. O jeito, embora ele não cuide de nós, é adorá-lo e nas piores circunstâncias ter o coração pleno do prazer de louvá-lo (SV, p.126).

Este aparente teocentrismo é, contudo, dialeticamente aposto a um radical ateísmo. A autora constrói uma teologia, mas uma teologia no sentido de uma ciência de deuses nào existentes. Ela opòe a fé de Angela Pralini ao ceticismo do narrador:

Eu inventei Deus - e não acredito n'Ele. É como se eu escrevesse um poema sobre o nada e me visse de repente encarando frente a frente o próprio. Deus é uma palaura? Se for estou cheio dele: milhares de palavras metidas dentro de um jarro fechado e que às vezes eu abro - e me deslumbro. Deuspalavra é deslumbrador (SV, p.126).

Nas últimas frases desta bela passagem, a autora reivindica as raízes etimológicas do termo "teologia," fazendo equivaler "Deus" a "palavra.". Em outras palavras, ele só acredita num deus que possa coalescer em pura linguagem. Neste processo de valorizaçào das palavias, temos um prodigioso exemplo de construção de um mundo metaficcional que nasce das ruínas do velho templo metafísico edificado sobre as fundaçòes da certeza, da verdade e da estabilidade.

A demoliçào desta velha ordem é, indubitavelmente o propósito da narrativa de Clarice. Este empreendimento só é possível através do constante retorno à linguagem e ao processo de escrita, através do escrutínio de seus mecanismos, da exposiçào de suas possibilidades e do questionamento de suas impossibilidades com o objetivo de revitalizar sua relaçào com a realidade. Apesar disso, neste primeiro momento a realidade externa parecer desnecessária, porquanto a transparência da linguagem dificulta um verdadeiro e autêntico acesso ao real: "Só me interessa escrever quando me surpreendo com o que escrevo. Eu prescindo da realidade porque posso ter tudo através do pensamento" (SV, p.90).

Num outro momento, o narrador sente a necessidade de retornar a uma pura realidade, mas imediatamente volta-se para o reino das palavras e do puro pensamento:

A realidade não me surpreende. Mas nào é verdade: de repente 
tenho uma tal fome da "coisa acontecer mesmo" que mordo num grito a realidade com os dentes, dilacerantes. E depois suspiro sobre a presa cuja carne comi. E por muito tempo, de novo, prescindo da realidade real e me aconchego em viver de imaginação (SV, p. 90).

O que Foucault disse a respeito de Roussel pode muito bem ser aplicado a Clarice Lispector: "Nào existe um sistema comum à linguagem e à existência, por uma simples razão: a linguagem sozinha forma um sistema de existência” (1986:161):

Eu sou autor de uma mulher que inventei e dei o nome de Angela Pralini. Eu vivia bem com ela. Mas ela começou a me inquietar e vi que eu tinha de novo que assumir o papel de escritor para colocar Angela em palavras porque só então posso me comunicar com ela (SV, p. 31).

A situação se torna mais complexa quando o narrador afirma que sua personagem é também escritora. Temos nesse caso um labirinto infindável de múltiplas superposiçòes: "Eu escrevo um livro e Angela outro: tirei de ambos o supérfluo" (SV, p. 31).

Ao rejeitar toda a superfluidade de ambos os discursos, o narrador está tentanto exercitar um certo poder sobre a criaçào. Na realidade ele não pode sequer controlar sua própria voz, repetindo automaticamente o que a personagem Angela diz: "Angela - Viver me deixa trêmula; Autor - A mim também a vida me faz estremecer (SV, p. 32).

Paulatinamente o personagem ganha mais e mais independência, e o narrador finalmente admite a impossibilidade de dominar por inteiro o produto de sua criação: Autor - Eu queria poder "curá-la" de si própria. Mas sua "doença” é mais forte que meu poder, sua doença é a forma de sua vida (SV, p. 48).

$\mathrm{Na}$ última parte do romance ("Livro de Angela"), a personagem criada pelo narrador tenta realizar o sonho de escrever um livro. Ela define seu interesse pelo empírico e decide compor um livro sobre "coisas". Nesta passagem, o narrador aceita a inteira independência de Angela em relaçào ao criador:

Ela é um personagem tão autônomo que se interessa por coisas que a mim autor não dizem respeito. Observo-a escrevendo sobre objetos. É um livre-estudo no qual não tomo parte. Enquanto para Angela as coisas são pessoais para mim o estudo da coisa é abstrato demais (SV, p. 99).

A tentativa de Angela de relacionar-se com o mundo resulta também falha. Sua percepçào da realidade empírica é tào diferente que ela transforma este mundo concreto que a atrai num vago e nebuloso universo. A aparente tangibilidade das 
coisas se transforma num evanescente quadro pintado pelo personagem. Numa desesperada obsessão em experimentar a concreção da realidade, ela tenta penetrar no reino dos objetos: "Entrei num reino silencioso do que é feito pela mào vazia do homem: entrei no domínio da coisa" (SV, p.104).

Seu contacto com a realidade empírica se transforma, desta maneira, numa experiência surreal. Apesar do aspecto sólido das coisas, ela se comunica com o mundo através de fluidas emanaçòes:

A aura é a selva da coisa. Emanações fluidicas me cegam ofuscantes a visão. Tremo trêmula. Tremulo tremida. Há algo de esquálido no ar. Aspiro-o sôfrega. Quero impregnar-me toda com as fisicas do que existe em matéria. 4 aura da ioisa vem do avesso da coisa (SV, p.104).

De acordo com Foucault, a verdadeira escritura começou quando se começou a se representar nào as coisas em si mas os elementos que as constituíam (1966:126). Em sua narrativa, Angela descreve a realidade da mesma maneira. Apesar de sua insistência em ser realista, a descriçào dos objetos é apenas um levantamento de certas qualidades desses mesmos objetos e das dificuldades de comunicar-se com eles. Ao escrever uma lista de nomes dos objetos e tentar penetrar na essência deles, ela finalmente toma consciência de que esta experiência é muito mais uma projeção de seus desejos do que pura realidade. A linguagem é um véu que a impossibilita de um contato puro com o mundo; mas, ao mesmo tempo, é o único meio de aproximação da realidade. Dessa forma, scu discurso consiste de meras especulações e conjecturas. O único momento no romance em que Lispector tenta ser "realista" é, de certa forma, frustrante. Ela sempre retorna à linguagem e ao jogo que seus elementos possibilitam. Autoreflexividade é, dessa forma, o traço decisivo de Um sopro de vida.

Movido por uma repetiçào compulsiva, o romance de Lispector desenvolve uma série de duplicaçòes que resulta em diferença. A diferença nào é um espaço separado, mas constitui a repetiçào mesma. Clarice Lispector escreve "en abyme." Quando Angela Pralini (um personagem inventado por outro personagem) escreve um livro e neste livro cita algumas das obras da própria Clarice, temos a imagem da narrativa circular:

No meu livro A cidade sitiada eu falo indiretamente no mistério da coisa. Há anos também descrevi um guarda-roupa. Depois veio a descrição de um imemorável relógio thamado Sveglia: relógio eletrônico que me assombrou e assombraria qualquerpessoa viva no mundo. Depois veio a ver do telefone. No "Oro e a galimha" falo no guindaste (SV, p.102). 
Este círculo não é, no entanto, um círculo fechado. Ele revolve em movimentos espiralares. Essa paixão pelo retorno é também uma paixão pelo devir. Apesar de inúmeros retornos e duplicaçòes, Um sopro de vida nunca começa ou termina.

Como num jogo de espelhos, combinando múltiplas perspectivas, Um sopro de vida possui um caráter transcendente, posto que desliza sub-repticiamente entre os possíveis centros criados pelas armadilhas autoritárias da linguagem. A metaficção, como um duplo movimento da repetição e diferença é, neste caso, um instrumento que torna possível esta transcendência. 